Etnográfica

Revista do Centro em Rede de Investigação em

Antropologia

vol. $16(2) \mid 2012$

Vol. $16(2)$

\title{
Gesù Cristo è il Signore: a Igreja Universal do Reino de Deus em Itália
}

Gesù Cristo è Il Signore: the Universal Church of the Kingdom of God in Italy

Donizete Rodrigues e Marcos de Araújo Silva

\section{(2) OpenEdition}

Journals

Edição electrónica

URL: https://journals.openedition.org/etnografica/1547

DOI: 10.4000/etnografica. 1547

ISSN: 2182-2891

\section{Editora}

Centro em Rede de Investigação em Antropologia

\section{Edição impressa}

Data de publição: 1 junho 2012

Paginação: 387-403

ISSN: 0873-6561

\section{Refêrencia eletrónica}

Donizete Rodrigues e Marcos de Araújo Silva, «Gesù Cristo è il Signore: a Igreja Universal do Reino de Deus em Itália», Etnográfica [Online], vol. 16 (2) | 2012, posto online no dia 26 junho 2012, consultado o 10 fevereiro 2022. URL: http://journals.openedition.org/etnografica/1547 ; DOI: https://doi.org/ 10.4000/etnografica.1547

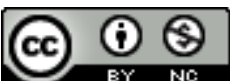

Etnográfica is licensed under a Creative Commons Attribution-NonCommercial 4.0 International License. 


\section{Gesù Cristo è il Signore: a Igreja Universal do Reino de Deus em Itália}

\section{Donizete Rodrigues e Marcos de Araújo Silva}

Com base em pesquisas etnográficas, este artigo trata da presença da Igreja Universal do Reino de Deus (IURD) em Itália, onde atua com o nome de Chiesa Cristiana dello Spirito Santo (CCSS), enfatizando o seu forte proselitismo e estratégia de implantação e a sua relação com os imigrantes, brasileiros e de outras minorias étnicas, e com os nacionais italianos. Exemplo de maior sucesso da transnacionalização do protestantismo brasileiro na sua vertente pentecostal e presente nos cinco continentes, a IURD-CCSS é analisada a partir de uma abordagem antropológica feita no contexto da problemática da diáspora brasileira e da reverse mission, dois fenómenos muito importantes e de grande interesse para as ciências sociais.

PALAVRAS-CHAVE: transnacionalismo religioso, pentecostalismo brasileiro, reverse mission, diáspora brasileira, IURD, Itália.

Gesù Cristo è Il Signore: the Universal Church of the Kingdom of Grod in Italy - Based on ethnographic research, this article focuses on the presence of the Universal Church of the Kingdom of God (UCKG) in Italy, where it operates under the name Chiesa Cristiana dello Spirito Santo (CCSS). It discusses the case of the UCKG in Italy with emphasis on its strong proselytism and deployment strategy, and its relationship with immigrants, Brazilian and from other ethnic minorities, and Italian nationals. The most successful example of transnationalization of Brazilian Protestantism in this Pentecostal trend and present on five continents, the UCKG-CCSS in Italy is analyzed trough an anthropological approach in the context of the Brazilian diaspora and the "reverse mission", two very important phenomena and of great interest for the social sciences.

KEYWORDS: religious transnationalism, Brazilian pentecostalism, reverse mission, Brazilian diaspora, IURD, Italy.

RODRIGUES, Donizete (donizetti.rodrigues@gmail.com) - Universidade da Beira Interior, Portugal; Centro em Rede de Investigação em Antropologia, Portugal.

SILVA, Marcos de Araújo (marcosimonstock@gmail.com) - Universidade Federal de Pernambuco, Brasil; Universidade Sapienza, Itália. 


\section{A RELIGIÃO, COMO FENÓMENO SOCIAL, COMO EXPRESSÃO SIMBÓLICA} das experiências sociais, é de primordial importância na análise de todas as sociedades humanas. ${ }^{1}$ É um elemento determinante para a compreensão da vida social, das práticas institucionais, para entender as experiências quotidianas e os processos de mudança social (Wilson 1982).

O fenómeno migratório internacional, principalmente depois da II Guerra Mundial, foi (e ainda continua a ser) extremamente importante na criação, expansão, dispersão e globalização dos novos movimentos religiosos, com um grande destaque para as igrejas (neo)pentecostais, abrangendo o triângulo religioso entre o Brasil, os Estados Unidos e a Europa (Beyer 2006; Clarke 2006; Rodrigues [no prelo]).

O fenómeno do neopentecostalismo, católico e protestante, surgiu nos Estados Unidos na década de 1960 e rapidamente se expandiu para diferentes partes do mundo, nomeadamente para a América Latina, com especial destaque para o Brasil. Em consequência disso, o neopentecostalismo é hoje um dos maiores movimentos religiosos do mundo (Coleman 2000) e o Brasil é o país com a maior concentração de pentecostais do mundo.

O processo de globalização e os grandes fluxos migratórios transcontinentais provocam significativas mudanças sociais, culturais, religiosas e identitárias. A principal consequência deste fenómeno migratório é que as sociedades contemporâneas estão cada vez mais plurais, do ponto de vista étnico, cultural e religioso (Pluss 2009).

A análise sociológica e antropológica do fenómeno religioso no contexto da globalização corrobora a enorme importância que a religião, através da migração maciça de pessoas, ocupa nas sociedades atuais (Yang e Ebaugh 2001). A religião torna-se particularmente importante quando as pessoas/grupos migram. As circunstâncias desfavoráveis da diáspora reforçam o sentimento de pertença e a religião desempenha, neste contexto, um papel muito importante na manutenção da identidade cultural, linguística e religiosa do grupo (Haddad, Smith e Esposito 2003).

Partindo dessas orientações teóricas, pretende-se abordar neste texto o caso da Igreja Universal do Reino de Deus em Itália, onde atua com o nome de Chiesa Cristiana dello Spirito Santo. Será dada especial ênfase ao seu forte proselitismo e estratégia de implantação em Itália e à sua relação com os imigrantes, brasileiros e de outras minorias étnicas, e com os nacionais italianos.

O trabalho de campo etnográfico em Roma envolveu ainda a participação nas atividades de duas igrejas católicas, que oferecem missas em português,

1 Este trabalho foi realizado no âmbito do projeto internacional "The Exporting of Latin American Pentecostalism and Catholic Charismatic Renewal: Re-Christianization of Europe”, coordenado por Paul Freston e desenvolvido no Center for the Study of Latin American Pentecostalism, financiado pela University of Southern California (Los Angeles, EUA). 
destinadas aos imigrantes brasileiros em Roma. Neste trabalho de campo constatou-se, em ambas as igrejas, a presença regular de cerca de vinte fiéis brasileiros nas missas dominicais.

Por outro lado, existem diversas igrejas evangélicas oriundas do Brasil e que contam com pastores e muitos fiéis brasileiros em Roma. Para além do estudo sobre a Chiesa Cristiana dello Spirito Santo, tema central deste artigo, o trabalho etnográfico envolveu a participação nos cultos de duas destas igrejas evangélicas (Batista Renovada e Congregação Cristã no Brasil), seguindo as indicações fornecidas por alguns interlocutores de que elas seriam as que mais reúnem fiéis brasileiros evangélicos em Roma e que também oferecem celebrações em português.

\section{RELIGIÃO E EMIGRAÇÃO: O CASO BRASILEIRO}

A partir do neopentecostalismo, surgiram no Brasil centenas (ou mesmo milhares) de novas igrejas evangélicas (Chesnut 1997). A partir do final dos anos de 1980, as principais igrejas, mas principalmente a Igreja Universal do Reino de Deus - IURD (Rodrigues 2006), seguindo inicialmente o grande fluxo emigratório de brasileiros (principalmente para os Estados Unidos e Europa), começaram um rápido e expressivo movimento de expansão internacional, constituindo hoje um importante e global fenómeno religioso (Mariz 2009).

A forte expansão do neopentecostalismo a partir da América Latina para os Estados Unidos e Europa ocorre dentro da denominada reverse mission (Freston 2010). Surgidas a partir do trabalho de evangelização do protestantismo europeu e pentecostal norte-americano, as igrejas protestantes pentecostais, principalmente brasileiras, consideram-se responsáveis pela importante "missão divina" de (re)cristianizar os Estados Unidos, que se desviaram da moral e da prática protestante, e a Europa, que passa por um forte processo de secularização/laicização.

O modelo de expansão mundial pentecostal segue normalmente as diásporas emigratórias, partindo das regiões periféricas (América Latina, África e Ásia) para áreas centrais, nomeadamente EUA/Canadá, Europa e Japão. No caso específico do pentecostalismo brasileiro, a expansão ocorre através do forte fluxo emigratório brasileiro, mas também através de missionários (católicos e principalmente protestantes) para essas regiões mais desenvolvidas que, extrapolando a "fronteira étnica brasileira", atuam com outros imigrantes e também com nacionais, como é o caso apresentado neste texto.

Partindo da reflexão de Ebaugh (2003), podemos afirmar que, no caso específico do contexto da imigração brasileira, as igrejas neopentecostais têm desempenhado um duplo e importante papel: a) ajudam a manter a identidade brasileira na diáspora; b) tentam adaptar-se à cultura da host society, onde elas agora estão inseridas. Neste último caso, mesmo utililizando um forte 
proselitismo religioso, a estratégia dessas igrejas é respeitar os traços culturais e identitários do país de acolhimento. Esta estratégia passa também por utilizar, não a língua portuguesa, mas a língua oficial da host society para converter outros grupos étnicos e principalmente os nacionais, como é o caso da IURD em Itália, tema deste trabalho.

\section{"SÍ, QUI SI PARLA ITALIANO": A IURD EM ITÁLIA}

Seguindo o seu eficiente modelo de expansão e internacionalização, Portugal foi um país estratégico para a IURD, uma porta de entrada na Europa ocidental, onde há uma presença significativa de imigrantes brasileiros (Ruth e Rodrigues 1999). Como afirmou Freston, "que a IURD tenha se expandido a outros países [...] não surpreende, mas sim a dimensão e velocidade dessa expansão” (1999: 385).

A instalação inicial da IURD em Itália, com o nome de Chiesa Cristiana dello Spirito Santo (CCSS), ocorreu em 1993 e foi feita seguindo a sua tradicional e conhecida prática - através da compra e arrendamento de espaços para a prática de culto, espaços estes localizados em áreas urbanas centrais. A sede nacional, a "catedral" (figura 1), foi estrategicamente instalada a poucos metros da movimentada Roma Termini, a principal estação central de comboios, não só de Roma, mas de toda a Itália.

A Igreja Universal, seguindo criteriosamente a sua estratégia de expansão e conversão evangélica em Itália, hoje tem salas de culto em várias cidades, como Milão, Nápoles, Mântua, Turim, Bari e Florença (onde também fizemos trabalho de campo), e grupos de oração (que normalmente se transformam em salas de culto) em Verona, Udine, Peschiera, Terracina, Sicília-Siracusa e Génova. Sobre o trabalho de evangelização no território italiano, o jornal Exército Universal da IURD, que possui versões impressas e online, afirmou em julho de 2010 que

“[...] a evangelização da Igreja Universal em solo italiano é maciça. Televisão, jornal, rádio e distribuição diária de folhetos pelas ruas das cidades, com o apoio dos grupos de evangelização e de 'resgate' colaboram para o crescimento evangelístico e pela busca da aceitação do Evangelho pelos italianos, já que é forte a influência religiosa no país. Essa determinação faz com que a cada dia mais e mais igrejas sejam abertas" (em < http://www. exercitouniversal.com.br/2010/07/igreja-universal-na-italia.html>).

O website da IURD em Itália (http://iurditalia.org/) também permite a visualização de vídeos de programas da Igreja e disponibiliza a rádio online Positiva, que funciona 24 horas por dia e cujo conteúdo, focado na propagação da doutrina da Igreja e no atendimento espiritual, é todo difundido em italiano. 


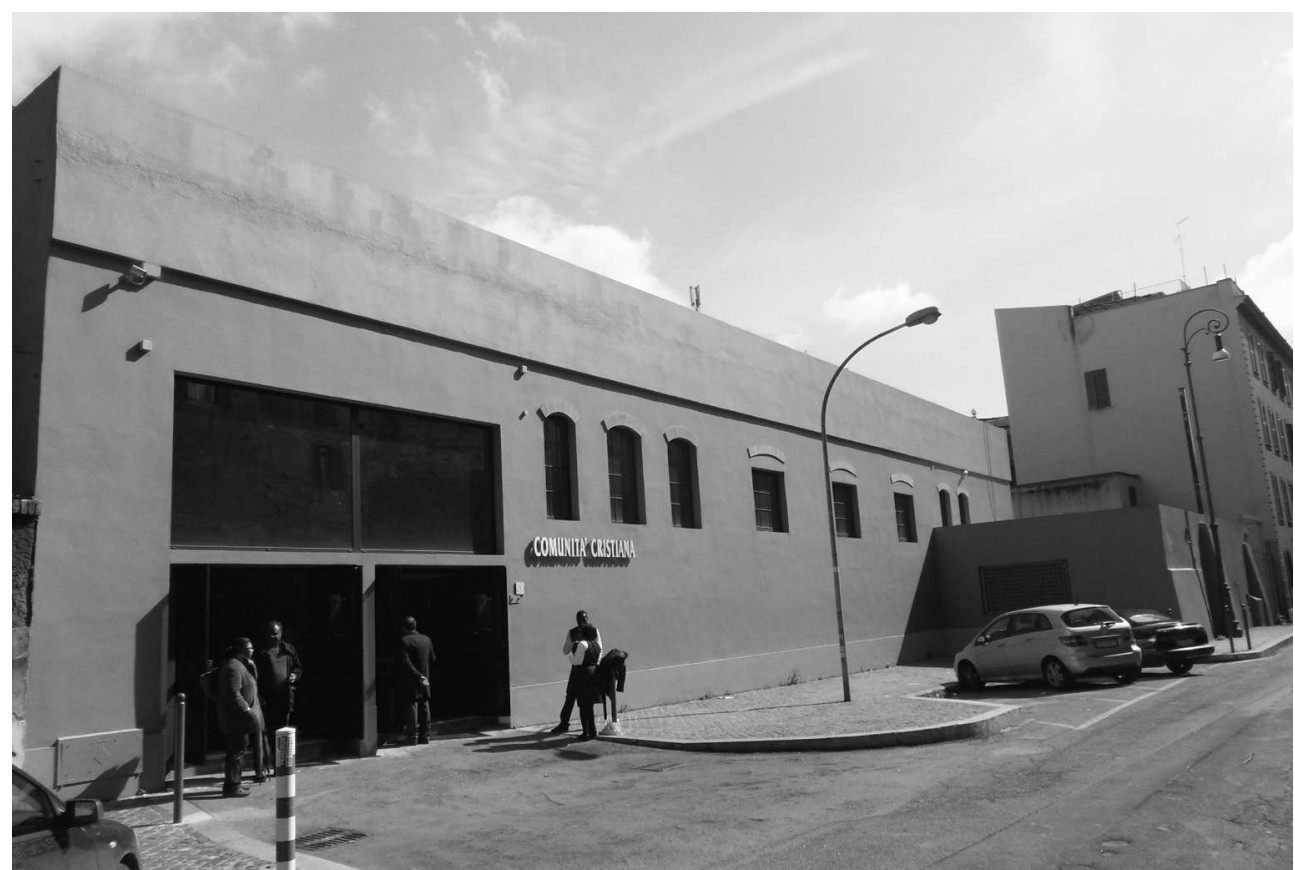

Figura 1 - A sede da IURD em Roma.

Via di Porta Tiburtina, 18/20. A 500 metros da já citada Roma Termini, a sede nacional da IURD italiana encontra-se frente a um monumento histórico. É um prédio moderno que, incluindo o seu estacionamento e a sua área de recreação, possui 150 metros quadrados. O imóvel custou 1.61 7.600,00 euros e o valor estimado da reforma e construção do novo prédio foi de $1.500 .000,00$ euros. ${ }^{2}$ Inaugurado em 27 de junho de 2010, o templo tem capacidade para abrigar 500 pessoas sentadas e fica aberto permanentemente, com quatro reuniões diárias e atendimento espiritual durante as 24 horas do dia. Antes da inauguração da sede nacional, entre 1993 e 2010, as reuniões na cidade ocorriam num pequeno salão no bairro de Casilino (periferia de Roma) que era chamado "templo provisório".

Segundo nos relatou (em 13/3/201 1) um fiel cabo-verdiano que participa no grupo de jovens da IURD romana, o então pastor do salão de Casilino, nas suas pregações, enfatizava sempre que o "aperto" e o caráter "temporário" daquele pequeno espaço daria lugar a um templo amplo, condizente com a fé e com o comprometimento com Deus dos fiéis italianos em geral. Participavam ativamente das atividades deste local de culto e contribuíam financeiramente para a manutenção deste "templo provisório" os seguintes fiéis: treze cabo-verdianos 
e nigerianos (dos quais nove eram mulheres) e seis brasileiros (dos quais quatro mulheres) que lá "aceitaram Jesus", segundo este interlocutor de 15 anos.

\section{UM DOMINGO NA IURD ROMANA}

Domingo, dia 6 de março de 2011. Chegámos à catedral-sede nacional da IURD italiana (figura 2) às $9 \mathrm{~h} 30$ da manhã. O pastor Leandro, que já conhecia um dos autores deste texto, estava neste dia em missão de trabalho em Milão. Fomos recebidos por uma obreira brasileira que, quando soube que éramos também brasileiros, perguntou o que estávamos a fazer em Itália e, no fim da (curta) conversa, disse-nos que uma graça iria acontecer neste dia nas nossas vidas. O bispo Wagner Simões presidiu ao culto, que durou duas horas, das 10 da manhã ao meio-dia. Notámos a presença de vinte obreiros no templo: quinze mulheres e cinco homens, todos elegantemente vestidos com os respetivos uniformes. Participaram no culto aproximadamente cem pessoas, predominantemente imigrantes de diferentes nacionalidades (muitos de origem africana e na sua maioria mulheres de meia idade), poucos brasileiros e uma pequena minoria de italianos/as.

Do lado direito do altar há uma citação bíblica, em italiano: "Se uno mi serve, Il Padre l'onorerà" (João, 12:26, ou: "Se alguém me serve, o Pai o honrará"). O culto começou com uma oração, feita pelo bispo Wagner Simões, para "purificar o corpo e a alma dos presentes". Além dele, havia outros dois pastores no altar: Pedro (português) e Andrade (brasileiro), todos elegantemente vestidos com fato de cor escura. Após a oração inicial, a pregação do bispo incidiu sobre quatro temas principais:

- Libertação - porque Deus quer que o homem seja livre

- Conversão - que implica mudanças na vida do crente

- Novo nascimento (born again) - o renascer numa nova espiritualidade

- O batismo no Espírito Santo - o que torna o fiel um espírito novo

O culto foi proferido em italiano, assim como todos os principais cultos que são feitos no templo. O culto deste dia era especial, pois marcava o início da Quaresma e, por isso, o número quarenta tinha um significado simbólico muito importante. Explorando liturgicamente este simbolismo, o bispo Wagner referiu várias vezes a importância de, neste período, se orar durante quarenta dias, para reforçar o vínculo com Deus e com a Igreja.

Um outro aspeto simbólico importante presente neste culto foi o momento das ofertas. Quando o bispo pede as contribuições, as ofertas, ele invoca primeiramente trinta pessoas para contribuírem com trezentos euros cada uma; isso simboliza os trinta dias do mês, cada fiel correspondendo a um dia. Após a solicitação do bispo, trinta pessoas dirigiram-se ao altar e pegaram nos 


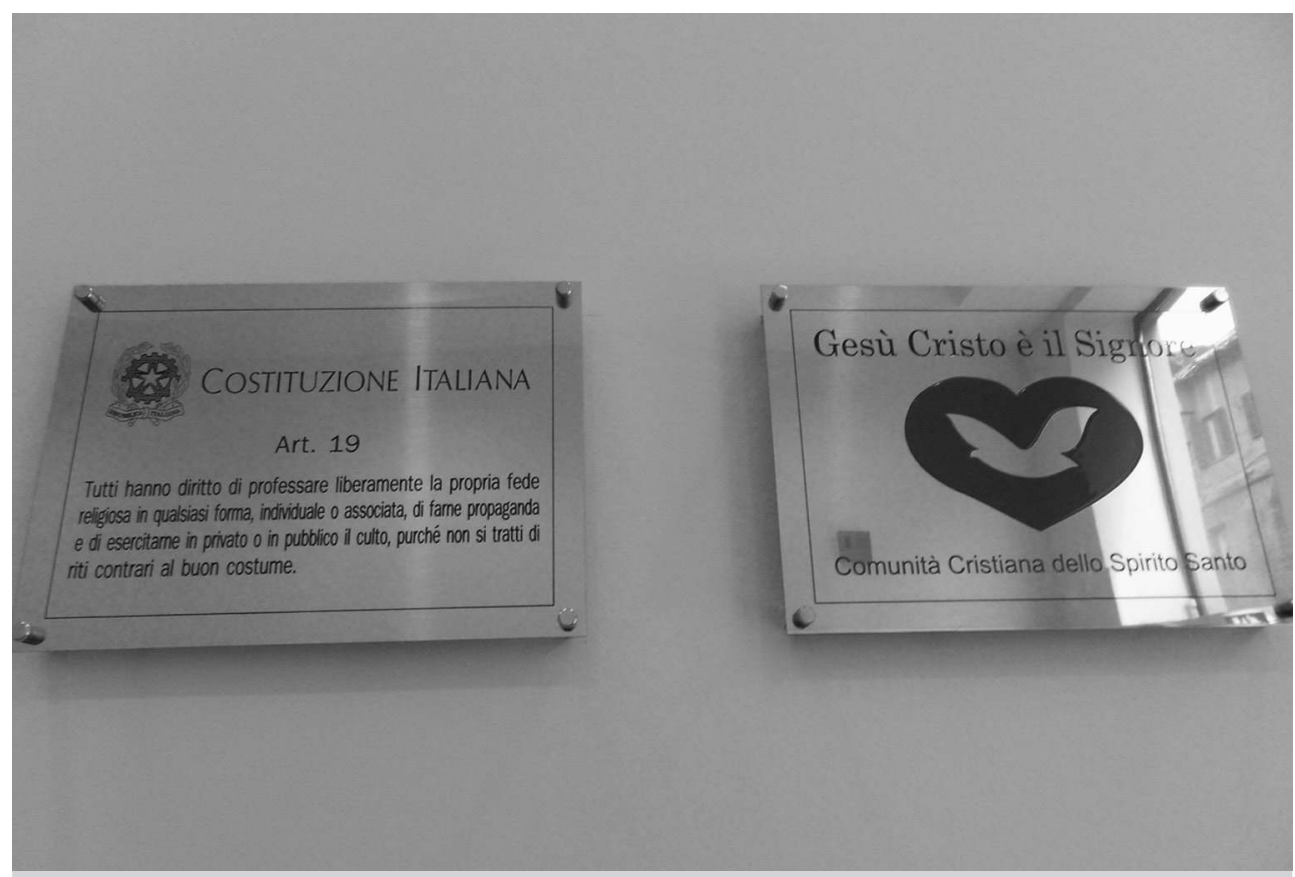

Figura 2 - Entrada principal do templo, com citação da legislação italiana sobre a liberdade religiosa. Ao lado, a placa da IURD italiana, com o tradicional símbolo da Igreja.

respetivos envelopes para as ofertas. Entre as trinta pessoas estavam quatro obreiros, sendo três mulheres. Esgotados os envelopes para a oferta de 300 euros, o bispo apela a que os fiéis doem cem euros. Finalmente, reforçando o aspeto simbólico da Quaresma, o bispo pede para todos os presentes doarem no mínimo quarenta euros cada um.

Num determinado momento do culto, o bispo chama os dizimistas ao altar em fila indiana para depositarem o envelope com dinheiro e receberem a unção com o óleo. Logo a seguir, baixaram uma enorme tela situada em frente ao altar, que permite a projeção de vídeos através de data-show, e começaram a exibir os testemunhos de fiéis recém-convertidos. Comprovando e reforçando a importância da conversão de nacionais, os depoimentos apresentados foram feitos por três italianos: duas mulheres e um homem. Para além dos pedidos dos trezentos, dos cem e dos quarenta euros, os obreiros começaram a passar as "sacolinhas" para receberem as ofertas.

Após o ofertório final, o bispo Wagner convidou os fiéis presentes para assinarem a bandeira italiana que cobria a mesa que se encontrava em destaque no altar (figura 3).

Sobre a mesa havia uma jarra de óleo para ungir os fiéis. Porquê este ritual da assinatura da bandeira italiana? Neste culto dominical faltavam onze dias 
para uma data especial para a República Italiana: o aniversário de 150 anos da unificação política do país, facto que ocorreu em 17 de março de 2011 .

Após a assinatura da bandeira italiana (que continuou presente no altar durante todo o mês de março de 2011), foram apresentados em vídeo mais três testemunhos de fiéis italianos. A mensagem segue um padrão: tinham problemas nas suas vidas (nas áreas profissional, de saúde e afetiva) e depois de começarem a participar nos cultos da Chiesa Cristiana dello Spirito Santo, e de "firmarem um vínculo com Deus", por meio da participação nas correntes de oração promovidas pela Igreja, viram as suas vidas completamente transformadas e não tiveram mais problemas, materiais e/ou espirituais.

O culto terminou e os fiéis presentes que participam no grupo de jovens do templo saíram juntos para almoçar num pequeno restaurante próximo do local. As atividades deste grupo ocorrem todos os domingos à tarde, às 14 h00. O pastor Andrade, oriundo de São Paulo, é o responsável e, neste dia, o grupo de jovens contava com dezessete elementos e uma maior igualdade entre os géneros: com predominância de africanos (cabo-verdianos e nigerianos na sua grande maioria) e a presença de um italiano e de um romeno.

A jovem Juliana, brasileira, esposa do pastor Andrade, que era uma das obreiras do culto da manhã, estava agora como participante no grupo de jovens, assumindo um papel de articuladora entre eles. Antes, como obreira no culto da manhã, Juliana usava uma roupa/uniforme e uma postura muito formal; agora estava vestida e comportava-se como uma adolescente. O pastor Andrade, igualmente, apresentava uma nova postura, bastante informal, era também um verdadeiro adolescente, que não se distinguia dos demais presentes: tinha trocado o fato escuro, usado no culto da manhã, por uma camisa desportiva, jeans e ténis. Ele cantou, dançou, pulou, tocou piano e deu até cambalhotas.

Os jovens pastor Andrade e a sua esposa Juliana demonstraram já conhecer todos os presentes, chamando-os pelos nomes. Ele falava de problemas comuns aos jovens, de questões/problemas que fazem parte das suas vidas quotidianas. Houve um concurso de dança hip hop e os jovens, bem alegres e descontraídos, dançaram juntos como se estivessem numa discoteca. A seguir houve um concurso de karaoke com canções pop. Samuel (um dos jovens presentes) e o pastor Andrade tocaram piano; este último tocou uma canção de Michael Jackson "You are not alone". Além disso, também houve exibições de kickboxing. Estas atividades diversificadas têm um propósito: trabalhar com os jovens o tema de que "ognuno ha il suo talento" (cada um tem o seu talento). Após uma oração, o pastor Andrade fez uma breve reflexão sobre este tema, que culminou com uma mensagem final deixada aos jovens: "Oggi tu fai la tua scelta, domani la tua scelta ti farà" (hoje tu fazes a tua escolha, amanhã a tua escolha te fará).

Essa reunião-culto do grupo de jovens não tem a estrutura de um culto normal e, reforçando a sua proposta de atrair e congregar jovens, mais parecia um 


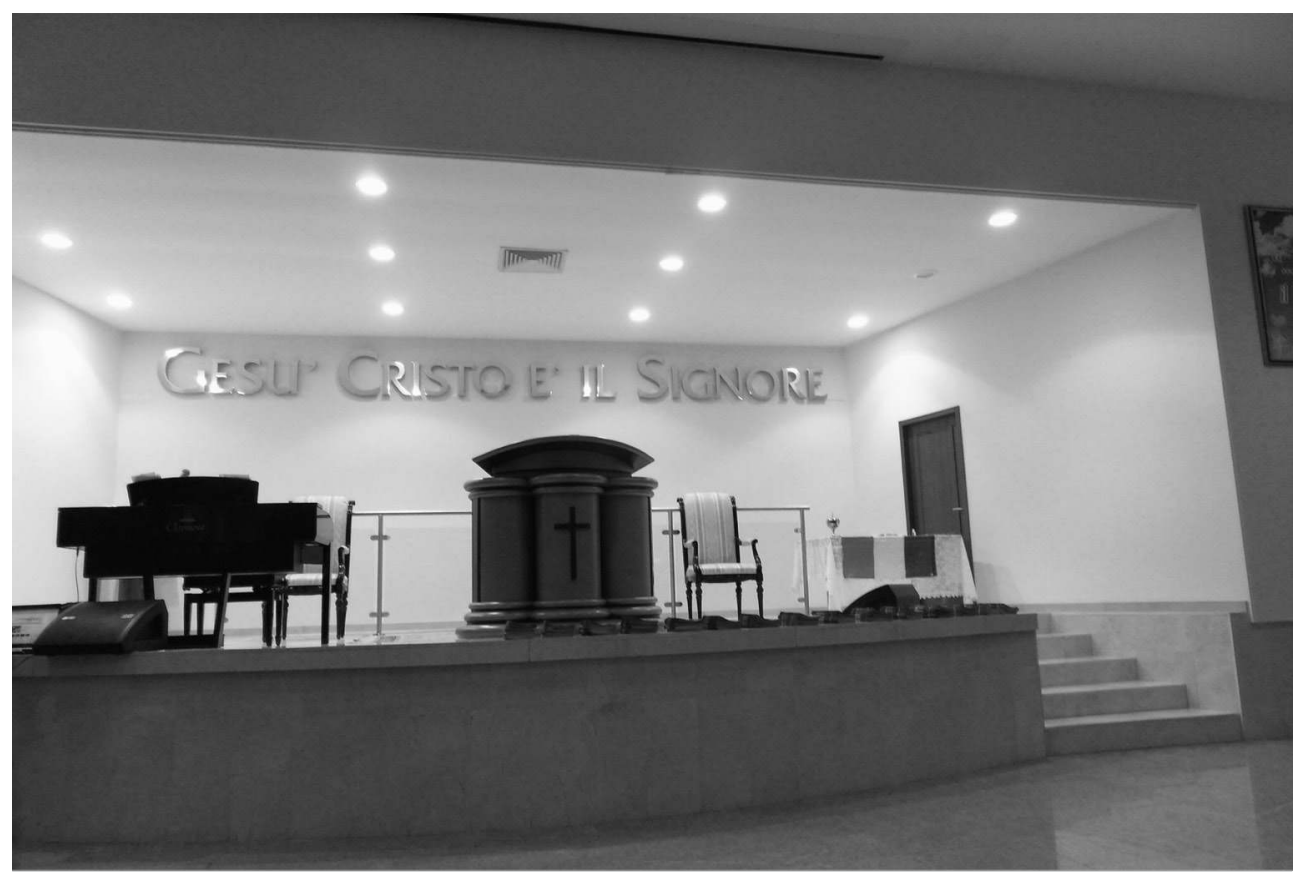

Figura 3 - O altar do templo, com a tradicional frase "Jesus Cristo é o Senhor", com a bandeira italiana cobrindo a mesa de cerimónias.

encontro comum de pessoas daquela idade. Todo o espaço foi especialmente preparado para atender os jovens. Havia no templo um ambiente acolhedor, bem iluminado e alegre. A música era tocada num volume bastante alto e luzes especiais foram acionadas, por exemplo. É interessante realçar que o Salmo 150 faz referência e até mesmo incentiva estes aspetos presentes no culto dos jovens e que podem ser caracterizados como "festivos". ${ }^{3}$ Tais características e estratégias festivas para atrair e congregar jovens também foram constatadas por Rodrigues [no prelo], a partir de uma pesquisa sobre a atuação de igrejas pentecostais brasileiras na área metropolitana de Nova Iorque. Esta atuação diferenciada e específica voltada para os jovens evidencia como a CCSS/IURD está consciente tanto da importância dos descendentes (segunda geração) de imigrantes para o seu crescimento enquanto instituição religiosa, quanto da sua possível influência na trajetória de vida destes jovens.

3 Conforme o Salmo 150 da Bíblia, o crente deve louvar ao Senhor com alegria: "Louvai-o ao som da trombeta; louvai-o com saltério e harpa. Louvai-o com adufe e com danças; louvai-o com instrumentos de cordas e com flauta. Louvai-o com os címbalos sonoros; louvai-o com címbalos altissonantes. Tudo quanto tem fôlego louve o Senhor" (Salmos, 150: 3-6). 
Para Alejandro Portes e Josh DeWind (2007: 17-22), a esfera religiosa tem sido menos um elemento determinante da migração e incorporação e tem conduzido mais a uma série de interaction effects (efeitos de interação) com outros fatores. Baseados em exemplos etnográficos da Europa e da América do Norte, os autores citam quatro importantes elementos: 1) o movimento religioso (no caso do presente texto, a Igreja Evangélica) raramente cria fluxos migratórios próprios, mas acompanha os emigrantes e muitas vezes atenua os impactos do processo migratório sobre os seus membros; 2) o movimento religioso não dita as políticas migratórias estatais, mas ajuda nas suas implementações ou, alternativamente, confronta-as quando percebe que elas podem ser prejudiciais aos seus interesses ou aos dos seus membros; 3) o movimento religioso raramente inicia atividades transnacionais, mas fortalece os seus membros através das conexões de igrejas, que se encontram em diversos pontos geográficos; 4) a esfera religiosa não cria o contexto social que é confrontado pela segunda geração de imigrantes, mas pode tornar-se uma força vital em conduzir os jovens e ajudá-los a integrar-se nas sociedades de acolhimento. ${ }^{4}$

Estes elementos relativos à esfera religiosa em contextos de migração, referidos por Portes e DeWind (2007), estão presentes na realidade dos grupos de brasileiros que vivem em Roma. O quarto elemento em particular, que se refere à "segunda geração", é muito pertinente, pois está em consonância com os desejos dos jovens: sete brasileiros (três do sexo masculino e quatro do sexo feminino, com idades entre os 14 e 17 anos) $)^{5}$ afirmaram que não querem o que classificam como "uma integração subalterna" (comum na vida dos filhos de outros grupos de imigrantes, segundo eles) e que a participação em instituições religiosas os ajudou a desenvolver, juntamente com as suas famílias, uma rede de "bons contactos", que foi e continuará a ser muito importante no futuro, para que consigam apoios e melhores condições no competitivo mercado de trabalho italiano. Ou seja, estes jovens de segunda geração perceberam que a esfera religiosa lhes pode proporcionar um maior capital social (Bourdieu e Wacquant 1992: 119) e consequente ascensão social.

4 Portes e DeWind (2007) realçam que sistematizaram estas ideias a partir de contextos sociais que encontraram em grandes cidades norte-americanas, mas que elas podem ser adaptadas e utilizadas para refletir sobre outras realidades socioculturais. Nos EUA, diversas instituições religiosas apoiam os imigrantes (latino-americanos, em particular), ajudando-os a preservar a sua língua e costumes, na educação dos filhos, proporcionando à segunda geração maior sucesso escolar e consequente ascensão social. Seguindo as ideias destes autores, Rodrigues (2012) verificou que existem diversas denominações religiosas protestantes (predominantemente pentecostais) de origem brasileira que atuam nos EUA e que fornecem apoio religioso e social aos imigrantes brasileiros naquele país.

5 Quatro são já nascidos em Itália, filhos de casamentos mistos ou relações afetivas entre italianos e brasileiras, e os outros três são jovens que migraram com os seus pais ou depois destes através do preceito jurídico da "reunificação familiar". Encontrámos três destes jovens na sede romana da CCSS e os outros quatro na igreja de Santa Maria della Luce, em Trastevere, que é a capelania católica dos sul-americanos em Roma. 


\section{A CHIESA CRISTIANA DELLO SPIRITO SANTO TAMBÉM ORA EM INGLÊS: O CULTO PARA A COMUNIDADE NEGRA}

Domingo, dia 6 de março de 2011 . O culto começou às 16 h00 e terminou às $17 \mathrm{~h} 00$. Estavam presentes uma imigrante latino-americana, sete africanas (cinco nigerianas) e uma afro-americana, casada com um italiano.

Os dois temas principais do culto foram Power (Força) e Faith (Fé). Todo o culto foi feito com as pessoas à frente no altar, em pé. Num momento de forte espiritualidade de oração coletiva e de imposição das mãos, uma fiel africana manifestou estado de possessão demoníaca. O exorcismo foi feito pelo pastor Pedro, um português que se converteu à IURD em Portugal e que é casado com uma portuguesa. O seu primeiro trabalho como pastor foi nos Estados Unidos (Califórnia), onde pregava em espanhol, visando converter a comunidade hispânica. Depois de passar por Londres, foi enviado pela hierarquia da IURD para ser pastor em Roma.

A única obreira presente neste culto era negra e chamava-se Esther. É importante notar que foi escolhida uma obreira negra porque o culto em causa era especialmente dedicado aos fiéis negros. Neste caso, para além de partilharem a mesma identidade religiosa (de serem todos evangélicos), há também a partilha da mesma pertença étnico-racial (de serem todos negros). A Esther é estudante oriunda da Nigéria e está há cinco anos em Itália. No culto anterior, ela era uma das participantes do grupo de jovens, liderado pelo pastor Andrade, tendo inclusive cantado no concurso de karaoke.

Como é prática na IURD, a importância do dízimo foi realçada pelo pastor durante todo o culto. Neste houve também a projeção em vídeo de testemunhos, em particular um em inglês, de uma afro-americana que falou sobre os problemas que ela enfrentava antes da sua conversão à IURD: infelicidade, problemas económicos e de saúde, decorrentes de um processo de depressão e desemprego. Ela testemunhou enfaticamente que, após a conversão, a sua vida mudou radicalmente e que todos os problemas foram sanados - "Hoje sou feliz, com saúde e com um bom emprego", concluiu. Em seguida, houve o testemunho presencial de uma mulher negra sul-africana, que falou sobre a sua experiência religiosa na IURD, testemunho este muito semelhante ao apresentado anteriormente na projeção em vídeo.

A grande maioria dos fiéis presentes estava com uma fita vermelha no pulso direito (colocada no culto do domingo anterior) que foi cortada pelo pastor Pedro. A fita simboliza a ligação do fiel com a Igreja, como uma corrente que o liga à instituição religiosa e que, além disso, lembra diariamente ao fiel que ele faz parte da Igreja. Após o corte da fita, ocorreu a colocação de uma nova fita vermelha no pulso dos presentes, reproduzindo e reforçando assim, simbolicamente, a união deles com a Igreja. Os fiéis ficam assim "amarrados"/ligados à Igreja, pois foram intimados a estarem presentes no culto do próximo fim de semana para renovação da fita/vínculo. 
Na saída do culto conhecemos Tiago, um ítalo-brasileiro nascido no Paraná, casado com uma brasileira e que tem uma filha pequena já nascida em Itália. Ele veio do Brasil diretamente para Roma, onde mora há três anos. Tiago comentou que, com a certidão de nascimento do seu avô, em três meses conseguiu a cidadania italiana, de maneira bem mais rápida e fácil do que se realizasse o pedido através dos consulados italianos no Brasil. É fiel da IURD desde os três anos de idade, juntamente com a sua família e o seu irmão chamado Murilo, pastor da Universal em Chelas, bairro de Lisboa. Tiago contou-nos que a Igreja tinha um culto em português, mas que resolveu atuar só em italiano e inglês. Quando nós lhe perguntámos "Mas porquê o culto somente em italiano?", ele respondeu prontamente: "Porque estamos na Itália".

\section{A IURD EM FLORENÇA}

Após a participação em vários cultos na catedral-sede em Roma, e para compreender melhor o processo de implantação da IURD em Itália, fomos fazer trabalho de campo etnográfico em Florença.

Sexta-feira, dia 11 de março de 2011. Chegámos ao templo da Chiesa Cristiana dello Spirito Santo às $10 \mathrm{~h} 20$ e assistimos somente ao fim do culto. Estavam presentes cinco mulheres brasileiras e um italiano da Sicília, todos aparentando estar na faixa etária de 30 anos. Conhecemos Mônica, cantora e compositora evangélica, natural de Pernambuco, mas criada em Maceió, que mora há onze anos em Itália. Converteu-se à IURD ainda no Brasil. Mônica possui um papel muito ativo dentro da Igreja, atuando inclusive como uma das principais evangelizadoras na cidade de Florença. Terminado o culto, começou a preparar-se para evangelizar não convertidos pelas ruas da cidade de Florença.

Este novo templo da CCSS em Itália foi inaugurado em 16 de janeiro de 2011. Como é estratégia da IURD, está localizado numa área central da cidade, de fácil acesso e próximo da estação principal de comboios, a Santa Maria Novella. Antes da inauguração deste templo, funcionava na cidade um grupo de oração, que se reunia numa parte mais afastada do centro da cidade. O pastor João Carleti mora há três anos em Itália, é natural do Espírito Santo (Brasil) e é responsável pelos grupos de jovens da IURD em todo o país. Este pastor contou-nos que era toxicodependente, a sua irmã foi a primeira da família a converter-se à IURD e que foi ela quem o levou à Igreja para que ele abandonasse o vício e se convertesse. O pastor Murilo, irmão do obreiro Tiago da sede nacional de Roma (do qual já falámos), que agora está em Lisboa, já atuou no grupo de oração de Florença.

O pastor João lidera ainda um grupo de oração na Sicília (Siracusa) e comentou que as negociações estão avançadas no intuito de abrir uma igreja nesta ilha. Quando mencionámos que tínhamos participado em cultos da IURD 
em Roma, ele confidenciou que para resolver o problema do embargo à obra da sede nacional de Roma (que durou dois anos e meio), a IURD contou com o apoio do senador Lúcio Malan, o único protestante do Senado italiano e que faz parte da Igreja Evangélica Valdense. ${ }^{6}$

O pastor João falou-nos ainda do projeto de, brevemente, poder abrir uma rádio de alcance regional (na Toscana) e que isso só não ocorreu até ao momento por conta da forte burocracia italiana. Segundo ele, a IURD na Europa está toda estruturada, bem coesa e com os seus membros e principalmente as suas lideranças interligadas e sempre em contacto através da Internet. Quando um dos etnógrafos mencionou que morava em Portugal, Mônica imediatamente disse que queria visitar este país e colocou para tocar na igreja um CD com uma canção da sua autoria e interpretação, para que escutássemos. No contexto da conversa, percebemos que ela tinha interesse em divulgar o seu trabalho em Portugal e, assim, tornar-se uma famosa cantora evangélica.

Segundo o pastor João, os italianos de uma maneira geral são "um povo de muita fé" e com quem é preciso "trabalhar com calma". A ideia é tentar levar a palavra de Cristo "sem confrontar com a fé deles", acrescentando o pastor que, sempre aberta ao diálogo, a IURD oferece as condições necessárias para que a aceitação e a conversão possam partir de cada um dos italianos que porventura venham conhecer o trabalho que a CCSS promove no país. Este pastor ainda fez referência à dificuldade que sente em expressar a palavra de Deus em italiano, em ter que escolher as palavras certas e precisas para explicá-la neste idioma.

Após esta visita ao templo da IURD em Florença, andámos pelos principais pontos turísticos da cidade e constátamos que, tanto os fiéis da IURD que estavam no culto, quanto os demais brasileiros/as que encontrámos no centro da cidade, apresentavam um perfil socioeconómico diferenciado daquele que conhecemos entre a maioria dos brasileiros que vivem em Roma: os que moram em Florença têm um maior nível educacional e uma melhor situação económica. Além disso, notámos a presença de muitos/as estudantes brasileiros/as descendentes de italianos e com a cidadania italiana, visto que a legislação de Itália segue o preceito do jus sanguinis.

6 A Igreja Evangélica Valdense é uma denominação religiosa italiana constituída antes da Reforma protestante do século XVI. Em 1975, uniu-se à Igreja Metodista Italiana e deu origem à Unione delle Chiese Metodiste e Valdesi (União das Igrejas Metodistas e Valdenses). Em Itália, é a principal minoria protestante/evangélica; dados recentes (dezembro de 2010) indicam que existem 25.693 fiéis desta Igreja. É integrante da Federazione delle Chiese Evangeliche in Italia (Federação das Igrejas Evangélicas na Itália), da Alleanza Mondiale delle Chiese Riformate (Aliança Mundial das Igrejas Reformadas) e do Consiglio Ecumenico delle Chiese (Conselho Ecumênico das Igrejas). É pertinente realçar que os seguidores da Igreja Valdense em Itália tiveram sempre um importante envolvimento político-partidário, nomeadamente em oposição ao partido da Democracia Cristã, de orientação católica. Tal facto explica, de certa forma, o apoio dado aos neopentecostais, como foi o caso da Igreja Universal do Reino de Deus. 
A IURD está consciente desta heterogeneidade, presente nos diversos grupos de brasileiros espalhados pelas principais cidades italianas, e tenta adaptar a sua estratégia de conversão a essas particularidades regionais e locais. Esta suposição foi confirmada por três interlocutores: João, cabo-verdiano de 58 anos, que frequenta a IURD romana com a sua esposa e os seus dois filhos adolescentes, e dois brasileiros, um obreiro e um fiel da IURD romana, que serão a seguir apresentados.

\section{O OBREIRO E O CONVERTIDO}

Roma, domingo, 13 de março de 2011 . Após o culto dominical, um dos etnógrafos pôde participar no almoço self-service que a igreja oferece aos seus fiéis ao custo de dez euros. Nesta ocasião, foi possível conhecer e conversar com Eduardo e Marivaldo, mais conhecido como Júnior.

O carioca Eduardo tem 35 anos e vive há seis na Europa, tendo passado temporadas em Barcelona e Pisa antes de chegar a Roma. Ele contou que já conhecia o trabalho da IURD no Brasil, mas que, de facto, só "aceitou Jesus" na IURD romana (CCSS) após o bispo Wagner Simões o ter retirado "da sarjeta", ainda toxicodependente, sem dinheiro e imigrante ilegal - sem o permesso di soggiorno (documento que permite aos estrangeiros a residência legal em Itália). Segundo Eduardo, depois de se tornar um membro fiel da IURD em Roma, regularizou a sua situação na Imigração italiana, conseguiu um trabalho e um local para morar, local este que lhe foi oferecido por Júnior.

O capixaba (natural do Espírito Santo) Júnior tem 33 anos e no Brasil estudou apenas até à quarta série do ensino fundamental. Sem chances de conseguir um bom emprego no Brasil, em virtude da sua baixa escolaridade, em 2006, Júnior aceitou o convite de um tio para ir para Itália e desde aquele ano trabalha numa fábrica em Ciampino, cidade integrada na área metropolitana de Roma. Quando questionado sobre porque ofereceu o sofá no seu pequeno apartamento de uma divisão para Eduardo morar, Júnior afirmou que já fez o seu "pé-de-meia", que pretende retornar ao Brasil brevemente e que quis deixar no coração de Eduardo a seguinte mensagem: ele deve ajudar outros brasileiros necessitados que procuram a IURD em busca de ajuda e, dessa maneira, continuar a "missão" que Deus conferiu aos iurdianos: "eu estou te ajudando agora p'ra que no futuro você ajude outras pessoas", disse Júnior ao receber Eduardo em sua casa.

Júnior contou ainda que já era membro da IURD no Brasil, tendo inclusive sido batizado no seu estado natal, o Espírito Santo. Porém, só em Roma se tornou um "verdadeiro fiel" e começou a "participar p'ra valer" na Igreja. Quando questionado sobre a razão disso, Júnior foi enfático: "Aqui é um outro mundo, aqui a gente vive em um deserto. O brasileiro aqui é ainda mais dividido e egoísta que lá no Brasil. Sem a ajuda da Igreja, eu nunca tinha me 
achado aqui”. Após a conversa, Júnior convidou o etnógrafo para participar no churrasco e na evangelização pelas ruas de Roma, que ele e outros fiéis da IURD romana iriam promover no domingo seguinte. Etnograficamente, não haveria melhor ocasião para conhecer ainda melhor a vida de Júnior e como funciona este trabalho de evangelização, por isso, o convite foi imediatamente aceite.

Domingo, 20 de março de $201 \mathrm{l}$. O etnógrafo chegou à IURD romana à hora do churrasco, às $12 \mathrm{~h} 30$, e aproximou-se de Júnior, que falou sobre a sua trajetória dentro da Igreja. Ele frequenta a IURD em Roma há três anos, desde o tempo em que a primeira sala de culto funcionava no "templo provisório" de Casilino. Tornou-se obreiro há dois anos, após ser "testado" diversas vezes pelo bispo Wagner e pelos outros pastores. Indagado sobre os "testes", Júnior respondeu que foram ações que visavam avaliar o seu nível de comprometimento e fidelidade com a "causa" da evangelização e que dois destes "testes" ocorreram da seguinte maneira: o pastor telefonou às $23 \mathrm{~h} 30$ para ele ir a uma reunião de preparação das atividades de evangelização que seriam feitas no dia seguinte; outro teste aconteceu quando ele se preparava para voltar para casa, depois de participar no culto da noite, após uma jornada inteira de trabalho, e o pastor, mesmo sabendo que ele estava com fome e cansado, convidou-o para uma atividade de evangelização, que na altura não foi especificada. Júnior, como um bom fiel, não pensou duas vezes e nem questionou do que exatamente tratava tal atividade ou a que horas ela terminaria. Júnior não sabia que estava a ser testado e só percebeu isso quando, num evento de convocação e formação de novos obreiros, o informaram que ele havia sido "escolhido" por Deus para a missão de ser um obreiro da IURD e atuar em Roma.

Após o churrasco, o etnógrafo participou na evangelização pelas ruas de Roma, com os fiéis que estavam presentes naquele evento: onze brasileiros (todos obreiros da Igreja e dos quais seis eram mulheres), dois casais de obreiros cabo-verdianos e sete jovens - três rapazes e uma jovem de Cabo Verde e três jovens mulheres da Nigéria, dentre estas Esther, da qual já falámos.

O trabalho de evangelização consistiu basicamente na distribuição de folhetos de divulgação do culto especial pela saúde, que ocorre todas as terças-feiras na igreja. Um aspeto interessante é que os pastores e obreiros da IURD presentes naquela atividade ignoravam nos seus discursos o facto de que Roma é a sede da Igreja Católica e sempre se referiam a esta cidade como uma terra "pagã" e "hedonista" que, por isso, "precisa ser evangelizada". Divididos em grupos de três ou de duas pessoas, cada grupo fazia a distribuição dos folhetos pelas caixas de correio dos apartamentos, pelos para-brisas dos carros e aos transeuntes que aceitavam as ofertas dos folhetos. O etnógrafo fez este trabalho com Júnior e Eduardo e, antes de terminar a atividade, dirigiu-se a Júnior demonstrando mais uma vez interesse pela sua trajetória dentro da IURD romana. Júnior concluiu dizendo: "Nós somos um exército, a gente é 
como um soldado que 'tá sempre pronto p'ra batalha e eu 'tou muito feliz por poder 'tar participando dessa missão".

\section{CONSIDERAÇÕES FINAIS}

Diversos estudos sociológicos e antropológicos já salientaram que, embora a maioria dos brasileiros emigrados se defina como "católica", o nível de pertencimento que estes apresentam em relação à Igreja é mínimo, esporádico ou simplesmente inexistente, ao contrário dos evangélicos (Rodrigues 2012).

Com base nas pesquisas etnográficas que realizámos no período de novembro de 2010 a abril de 2011 , podemos afirmar que, em Itália, sem contar com a presença de turistas e visitantes esporádicos, dentre as instituições religiosas, sejam elas católicas ou evangélicas, a que mais consegue reunir fiéis brasileiros de maneira regular é a IURD-CCSS. Esta realidade é um dos reflexos dos profundos impactos sociais que a transnacionalização do protestantismo brasileiro, na sua vertente pentecostal, promove mundo afora, como é o caso aqui abordado da capital italiana, sede da histórica e tradicional Igreja Católica romana.

Ligando o Brasil e a Itália através da esfera religiosa, no contexto do transnacionalismo protestante-pentecostal, neste artigo discutimos o caso da Igreja Universal do Reino de Deus em Itália, onde atua com o nome de Chiesa Cristiana dello Spirito Santo. Foi dada ênfase ao seu forte proselitismo e estratégia de implantação em Itália e à sua relação com os imigrantes, brasileiros e de outras minorias étnicas, e com os nacionais italianos. A abordagem antropológica foi feita no contexto da problemática da diáspora brasileira e da reverse mission, dois fenómenos muito importantes e de grande interesse para as ciências sociais. Por isso, são importantes e necessários mais estudos sobre as especificidades do fenómeno da diáspora brasileira/pentecostalismo noutros países onde haja uma expressiva presença de imigrantes brasileiros para, dessa forma, poder compreender melhor as inúmeras interfaces que tal fenómeno apresenta nas esferas religiosa, política, económica, social e demográfica no mundo contemporâneo. 


\section{BIBLIOGRAFIA}

BEYER, Peter, 2006, Religions and Global Society. Londres, Routledge.

BOURDIEU, Pierre, e Loïc WACQUANT, 1992, An Invitation to Reflexive Sociology. Chicago,

University of Chicago Press.

CHeSnut, R. Andrew, 1997, Born Again in Brazil: The Pentecostals Boom and Pathogens of Poverty. Londres, Rutgers University Press.

CLARKE, Peter (org.), 2006, Encyclopedia of New Religious Movements. Nova Iorque, Routledge. COLEMAN, Simon, 2000, The Globalization of Charismatic Christianity: Spreading the Gospel of Prosperity. Cambridge, Cambridge University Press.

EBAUGH, Helen R., 2003, "Religion and the new immigrants", em Michele Dillon (org.), Handbook of the Sociology of Religion. Cambridge, Cambridge University Press, 225-239.

FRESTON, Paul, 1999, "A Igreja Universal do Reino de Deus na Europa”, Lusotopie, 1 (2): 383-403.

—, 2010, "Reverse mission: a discourse in search of reality?", PentecoStudies, 9 (2): 153$-174$.

HADDAD, Yvonne Yazbeck, Jane I. SMITH, e John L. ESPOSITO, 2003, Religion and Immigration: Christian, Jewish and Muslim Experiences in the United States. Walmut Creek, CA, Altamira Press.

MARIZ, Cecília L., 2009, “Missão religiosa e migração: ‘novas comunidades’ e igrejas pentecostais brasileiras no exterior", Análise Social, XLIV (190): 161-187.

PLUSS, Caroline, 2009, "Migration and the globalization of religion", in Peter Clarke (org.), The Oxford Handbook of the Sociology of Religion. Oxford, Oxford University Press, 491-506. PORTES, Alejandro, e Josh DeWIND, 2007, "A cross-Atlantic dialogue: the progress of research and theory in the study of international migration", em Alejandro Portes e Josh DeWind (orgs.), Rethinking Migration: New Theoretical and Empirical Perspectives. Nova Iorque/Oxford, Berghahn Books, 3-26.

RODRIGUES, Donizete, 2006, "Universal Church of the Kingdom of God", em Peter Clarke (org.), Encyclopedia of New Religious Movements. Nova Iorque, Routledge, 593-595.

—, [no prelo], "The brazilianization of New York City: Brazilian immigrants and evangelical churches in a pluralized urban landscape", em Richard Cimino et al. (orgs.), Ecologies of Faith in New York City: The Evolution of Religious Institutions. Bloomington, Indiana University Press.

—, 2012, Jesus in Sacred Gotham: Brazilian Immigrants and Pentecostalism in New York City (inédito).

RUTH, Anders, e Donizete RODRIGUES, 1999, Deus, o Demónio e o Homem: O Fenómeno Igreja Universal do Reino de Deus. Lisboa, Colibri.

WILSON, Bryan, 1982, Religion in Sociological Perspective. Oxford, Oxford University Press.

YANG, Fenggang, e H. R. EBAUGH, 2001, “Transformations in new immigrant religions and their global implications", American Sociological Review, 66: 269-288. 